\title{
Influence of SLCO1B1 in gastric cancer patients treated with EOF chemotherapy
}

\author{
WANJING FENG ${ }^{1,2^{*}}$, XIN LIU $^{1,2^{*}}$, XIAOYING ZHAO ${ }^{1,2}$, MINGZHU HUANG ${ }^{1,2}$, \\ WEIJIAN GUO ${ }^{1,2}$, JILIANG YIN ${ }^{1,2}$, ZHIYU CHEN $^{1,2}$ and XIAODONG ZHU ${ }^{1,2}$ \\ ${ }^{1}$ Department of Medical Oncology, Fudan University Shanghai Cancer Center; \\ ${ }^{2}$ Department of Oncology, Shanghai Medical College, Fudan University, Shanghai 200032, P.R. China
}

Received November 19, 2017; Accepted June 28, 2018

DOI: $10.3892 / \mathrm{ol} .2018 .9147$

\begin{abstract}
Cytochrome-P450 enzymes, ATP-binding cassette transporters, and solute carriers mediate drug metabolism as metabolic enzymes and membrane transporters, respectively. The present study investigated whether single nucleotide polymorphisms (SNPs) in genes encoding these proteins were predictive or prognostic factors in patients with metastatic gastric cancer (MGC) undergoing chemotherapy. A retrospective study of 108 MGC patients who received epirubicin, oxaliplatin, and 5-fluorouracil (EOF) as first-line treatment was performed. A total of 13 SNPs were genotyped, including SLCO1B1 (rs4149056), SLC2A9 (rs16890979, rs6449213, rs734553), ABCG2 (rs2231142), CYP2C9 (rs1057910, rs1799853), CYP2C19 (rs72552267, rs28399504, rs56337013, rs41291556) and CYP1A2 (rs12720461, rs56107638). The associations between these genotypes and disease-control rate (DCR), progression-free survival (PFS) and overall survival (OS) were analyzed. Patients with SLCO1B1 rs4149056 TT genotype had a significantly shorter OS compared with those with a $\mathrm{C}$ allele $(\mathrm{CC}+\mathrm{CT} ; 312$ vs. 565 days, $\mathrm{P}=0.039$ ). Multivariate analysis revealed that the rs4149056 TT homozygous genotype was an independent prognostic factor for shorter OS (hazard ratio: $2.565,95 \%$ confidence interval: $1.215-5.415, \mathrm{P}=0.014)$. However, no significant associations between SLCO1B1 rs4149056 and PFS were observed, between the other 12 SNPs and PFS or OS, or between any of the 13 SNPs and DCR. In conclusion, SLCO1B1
\end{abstract}

Correspondence to: Dr Xiaodong Zhu or Dr Zhiyu Chen, Department of Oncology, Shanghai Medical College, Fudan University, 270 Dong' An Road, Shanghai 200032, P.R. China

E-mail: xddr001@163.com

E-mail: chanhj75@aliyun.com

*Contributed equally

Key words: gastric cancer, single nucleotide polymorphism, received epirubicin, oxaliplatin, and 5-fluorouracil regimen, SLCO1B1 rs4149056 TT may be an independent predictor of survival in patients with MCG treated with EOF chemotherapy.

\section{Introduction}

Gastric cancer (GC) represents the fourth most common malignant neoplasm and the second leading cause of cancer-related death worldwide. More than $40 \%$ of all GC cases diagnosed annually occur in China, of whom almost $50 \%$ are diagnosed at an advanced stage and cannot be cured. Treatment of advanced GC is challenging. Epirubicin, cisplatin, and fluorouracil (ECF) and its modified regimens, such as EOF (epirubicin, oxaliplatin, and fluorouracil) and EOX (epirubicin, oxaliplatin, and capecitabine), are widely used to treat GC patients based on the results of phase III clinical trials. However, although these regimens are common first-line treatments, their response rates remain $<50 \%$. Biomarkers able to predict chemotherapeutic efficacy are therefore urgently needed.

Both membrane transporters and metabolic enzymes affect cytotoxic-drug metabolism. Solute carrier (SLC) superfamily proteins and ATP-binding cassette (ABC)-transporters are vital membrane transporters. SLCO1BI encodes the transporter protein, organic anion-transporting polypeptide-1 (OATP1B1), which mediates liver uptake of a wide variety of drugs, and its role in the efficacy of cytotoxic drugs, including 5-fluorouracil (5FU) $(1,2)$, methotrexate (MTX) (3-5), irinotecan $(6,7)$, and paclitaxel (8) has been widely reported. MTX was the first cytotoxic drug reported to be associated with SLCO1B1, and SLCO1B1 SNPs were shown to affect MTX pharmacokinetics in children with acute lymphoblastic leukemia, particularly in terms of deposition and toxicity (5). These findings have been validated in several later studies (9-11). The breast cancer resistance protein (BCRP/ABCG2) has been reported to affect drug resistance in many cancer types, including colorectal cancer, lymphoblastic leukemia, and breast cancer (12-15), and $\mathrm{ABCG} 2$ polymorphisms are prognostic factors in breast cancer patients treated with anthracycline-based neoadjuvant chemotherapy (16). Expression levels of glucose transporters (GLUT/SLC1A) were also shown to be related to response to 5FU chemotherapy in GC cells (17), and glucose transporters were reported to be independent prognostic factors in patients with GC $(18,19)$. 
Among metabolic enzymes, the cytochrome-P450 (CYP) enzyme family plays an important role in the metabolism of various anticancer drugs (20). Several studies have shown that SNPs in $C Y P 2 C 9$ influence disease-free survival in breast cancer patients treated with tamoxifen $(21,22)$. Moreover, CYP2C9 polymorphism was related to response to fluorouracil-based neoadjuvant chemotherapy in breast cancer (23). CYP2C19 is involved in the metabolism of cyclophosphamide $(24,25)$ and tamoxifen $(26,27)$, and P450 enzymes in human liver microsomes, including CYP1A2 have also been reported to catalyze tegafur into $5 \mathrm{FU}$ (28).

Metabolism-related genes, including SLCO1B1, ABCG2, $S L C 2 A 9, C Y P 2 C 9, C Y P 2 C 19$, and $C Y P 1 A 2$, might thus influence the efficacy of EOF regimens. In the present study, we investigated the associations between metabolism-related genes and the clinical outcomes of GC patients treated with first-line EOF regimens, in terms of disease-control rate (DCR), progression-free survival (PFS), and overall survival (OS).

\section{Materials and methods}

Study population. This retrospective study enrolled 108 consecutive Chinese Han patients with metastatic GC (MGC) treated with EOF regimens as first-line chemotherapy at Fudan University Shanghai Cancer Center (Shanghai, China) between May 2009 and June 2012. Their diagnoses were pathologically confirmed as gastric adenocarcinoma. The study was approved by the Ethics Committee of Fudan University Shanghai Cancer and complied with the principles of the Helsinki Accord. This was a retrospective study and patient consent was therefore deemed unnecessary. However, blood samples were collected from all subjects before treatment, with patient consent, and stored in the tissue bank at Fudan University Shanghai Cancer Center.

Treatment. All patients in this study were treated with first-line chemotherapy using an EOF regimen, consisting of epirubicin infusion $\left(50 \mathrm{mg} / \mathrm{m}^{2}\right)$ combined with an intravenous infusion of oxaliplatin $\left(130 \mathrm{mg} / \mathrm{m}^{2}\right)$ for $2 \mathrm{~h}$ on day 1 , following a $24-\mathrm{h}$ continuous infusion of $5 \mathrm{FU}\left(375-425 \mathrm{mg} / \mathrm{m}^{2} /\right.$ day) for 5 days, over a 21-day treatment cycle. Tumor responses were evaluated every 6 weeks in accordance to the Response Evaluation Criteria in Solid Tumors 1.0 (RECIST 1.0). Treatment was terminated in the event of disease progression or unacceptable toxicity. If the lesions continued to shrink after six cycles, with no unacceptable toxicity, a further one or two EOF cycles were recommended; otherwise, oral FU was recommended as follow-up treatment.

SNP selection and genotyping. We selected and genotyped 13 drug-metabolism-related genetic polymorphisms located at SLCO1B1 (rs4149056), SLC2A9 (rs16890979, rs6449213, rs734553), $A B C G 2$ (rs2231142), CYP2C9 (rs1057910, rs1799853), CYP2C19 (rs72552267, rs28399504, rs56337013, rs41291556), and CYP1A2(rs12720461,rs56107638), respectively, from the Hapmap project (www.hapmap.org) and dbSNP databases (www.ncbi.nlm.nih.gov/SLP) (Table I). Genomic DNA was extracted from venous blood leukocytes using a standard phenol-chloroform method. The selected SNPs were genotyped using the TaqMan assay method and an ABI 7900
DNA detection system (Applied Biosystems, Foster City, CA, USA). All the probes and primers were designed using the Assay-on-Design service from Applied Biosystems. The experiments were repeated for $15 \%$ of the samples. The genotype error rate was $<0.03 \%$.

Statistical analysis. The allelic and genotypic distributions and Hardy-Weinberg equilibrium were analyzed using the online analysis tool, SHEsis. Differences in clinical characteristics among the $108 \mathrm{GC}$ patients were analyzed by $\chi^{2}$ tests, and differences in allelic and genotypic frequencies between the controlled-disease and progressive-disease groups were compared with $\chi^{2}$ or Fisher's exact probability tests. Genetic power was calculated using the $G^{*}$ Power program (29). Survival curves were analyzed using the Kaplan-Meier method. Differences in PFS and OS between genotype groups were estimated by log-rank tests. Multivariate analysis of prognostic predictors was carried out using a Cox proportional hazards model. A two-sided P-value $<0.05$ was considered significant. P-values for association analysis were corrected by a false-discovery rate (FDR) procedure (30). To be detailed, FDR $p=p^{*} n / a$. In this formula, $n$ is the number of SNPs in the same gene, and a is the rank of the P-value among the SNPs in the same gene.

\section{Results}

Patient characteristics. Most of the 108 GC patients enrolled in the study had $\geq 3$ tumor sites, with the most common metastatic organs being the liver and retroperitoneal lymph nodes. Among the clinicopathological features, liver metastasis and pleural effusion were significantly associated with OS, whereas histological grade, number of tumor sites, retroperitoneal lymph node involvement, and ascites were significantly associated with PFS (Table II).

The responses to EOF chemotherapy were $\mathrm{CR}, \mathrm{n}=1 ; \mathrm{PR}$, $\mathrm{n}=41$; SD, $\mathrm{n}=47$; and PD, $\mathrm{n}=19$. The 89 patients with $\mathrm{CR}, \mathrm{PR}$, or SD were classified as the disease-control group and the 19 patients with PD were classified as the disease-progression group.

Genotype frequency and disease control. There was no significant relationship between genotype frequency and disease-control rate for any of the 13 SNPs analyzed in the present study (Table III). There was only one genotype distribution each for $C Y P 2 C 19$ (rs72552267, rs28399504, rs56337013, rs41291556) and CYP1A2 (rs12720461, rs56107638) in the 108 patients (data not shown).

Genotype frequency and survival analysis. Univariate analysis of the 13 SNPs in relation to survival (Table IV) showed that patients with SLCO1B1 rs4149056 CC and CT genotypes had significantly longer median OS than patients with the TT genotype (565 vs. 312 days, log-rank $\mathrm{P}=0.039$; Fig. 1). However, there was no significant association between PFS and SLCO1B1 rs4149056 (log-rank P=0.956; Fig. 2), or between any of the other 12 SNPs and OS or PFS (Table IV).

Multivariate PFS and OS analysis with cox regression. Multivariate analysis showed that SLCO1B1 rs4149056 
Table I. SNPs in the SLCO1B1, SLC2A9, SLC17A1, ABCG2, CYP2C9, CYP2C19 and CYP1A2 genes analyzed in the article.

\begin{tabular}{|c|c|c|c|c|c|}
\hline Gene & SNP ID & Chromosome & Function & Allele & $\begin{array}{c}\text { HWE test } \\
\text { P-value }\end{array}$ \\
\hline SLCO1B1 & rs4149056 & $12: 21178615$ & Missense & $\mathrm{T} / \mathrm{C}$ & 0.608 \\
\hline SLC2A9 & rs 16890979 & 4:9920543 & Missense & $\mathrm{C} / \mathrm{T}$ & 0.903 \\
\hline SLC2A9 & rs6449213 & 4:9992591 & Intron & $\mathrm{C} / \mathrm{T}$ & 0.903 \\
\hline SLC2A9 & rs734553 & $4: 9921380$ & Intron & $\mathrm{A} / \mathrm{C}$ & 0.903 \\
\hline ABGC2 & rs2231142 & $4: 88131171$ & Missense & $\mathrm{A} / \mathrm{C}$ & 0.047 \\
\hline CYP2C9 & rs 1057910 & 10:94981296 & Missense & $\mathrm{A} / \mathrm{C}$ & 0.808 \\
\hline СYP2C9 & rs 1799853 & $10: 94942290$ & Missense & $\mathrm{C} / \mathrm{T}$ & 1.000 \\
\hline CYP2C19 & rs72552267 & 10:94775453 & Missense & $\mathrm{A} / \mathrm{G}$ & 1.000 \\
\hline CYP2C19 & rs28399504 & 10:94762706 & Missense & $\mathrm{A} / \mathrm{G} / \mathrm{T}$ & 1.000 \\
\hline СТР2C19 & rs 56337013 & $10: 94852738$ & Missense & $\mathrm{C} / \mathrm{T}$ & 1.000 \\
\hline CYP2C19 & rs41291556 & 10:94775416 & Missense & $\mathrm{C} / \mathrm{T}$ & 1.000 \\
\hline CYP1A2 & rs 12720461 & $15: 74749010$ & Intron & $\mathrm{C} / \mathrm{T}$ & 1.000 \\
\hline CYP1A2 & rs56107638 & $15: 74753271$ & Splice donor & $\mathrm{A} / \mathrm{C} / \mathrm{G}$ & 1.000 \\
\hline
\end{tabular}

HWE, hardy-weinberg equilibrium; SNP, single nucleotide polymorphism.

genotype, liver metastasis, ascites, pleural effusion, and number of tumor sites were significantly or borderline-significantly associated with OS (Table V). In addition, histological grade, retroperitoneal lymph node involvement, ascites, pleural effusion, and number of tumor sites were significantly or borderline-significantly associated with PFS. All the above factors were included in a stepwise multivariate Cox regression model, which confirmed that SLCO1B1 rs4149056 was an independent prognostic factor for shorter OS $(\mathrm{P}=0.014)$, but not PFS $(\mathrm{P}=0.533)$.

Linkage disequilibrium analysis. We analyzed linkage disequilibrium (LD) for the SLC2A9 and CYP2C9 SNPs in AGC patients HaploView software. The SLC2A9 SNPs rs16890979 and rs6449213 ( $\left.\mathrm{D}^{\prime}=1.000, \mathrm{r}^{2}=0.796\right)$, SLC2A9 SNPs rs16890979 and rs734553 ( $\left.D^{\prime}=1.000, \mathrm{r}^{2}=1.000\right)$ and SLC2A9 SNPs rs6449213 and $r s 734553\left(\mathrm{D}^{\prime}=1.000, \mathrm{r}^{2}=0.796\right)$ all showed strong LD (Fig. 3A). CYP2C9 SNPs rs1057910 and $\mathrm{rs} 1799853$ showed no LD $\left(\mathrm{D}^{\prime}=1.000, \mathrm{r}^{2}=0.000\right)$ (Fig. $\left.3 \mathrm{~B}\right)$. Since the most samples showed the same allele and only less than 5 samples showed different allele in the SCL2A9 SNPs, linkage disequilibrium and haplotype analysis cannot find clinically meaningful result.

\section{Discussion}

We investigated the association between SNPs of metabolism-related genes and chemotherapy response in patients with MGC. Patients with SLCO1B1 rs4149056 CC and CT genotypes had longer OS than patients with TT genotype (312 vs. 565 days, $\mathrm{P}=0.039$ ), and SLCO1B1 rs4149056 TT was confirmed as an independent prognostic factor for shorter OS in GC patients treated with EOF by Cox regression analysis (hazard ratio: 2.565, 95\% confidence interval: $1.215-5.415, \mathrm{P}=0.014)$.

SLCO1B1 encodes the SLC family member OATP1B1, which is highly expressed in hepatocytes and associated with hepatic drug uptake and elimination (31). Among single-nucleotide variants of $S L C O 1 B 1$, c.521T>C rs4149056 had the greatest effect on OATP1B1 activity in this study. SLCO1B1 c.521T $>\mathrm{C}$ decreases OATP1B1 transporting activity, thus increasing plasma concentrations of drugs, including cytotoxic drugs. SLCO1B1 rs4149056 has been significantly associated with exposure to $\mathrm{SN}-38$, the active metabolite of irinotecan (7). In another study, OATP1B1 was responsible for SN-38 uptake from plasma into hepatocytes (6). Innocenti et al also revealed that SLCO1B1 rs4149056 increased patient exposure to CPT-11 and was associated with an increased risk of severe neutropenia (6). OATP1B1 was shown to transport paclitaxel in an in vitro ovarian cancer study, implying that it contributed to the disposition of paclitaxel (8). Huang et al reported that another SLCO1B1 variant, rs2306283, was an independent prognostic factor for longer PFS in patients with metastatic colorectal cancer treated with a fluoropyrimidine plus irinotecan (1). Overall, these studies suggest that SLCO1B1 affects the metabolism of fluoropyrimidines, CPT-11, and docetaxel, thus influencing their chemotherapeutic efficacy, consistent with the results of the current study.

To the best of our knowledge, the present study provides the first evidence for an association between SLCO1B1 and GC. A literature search of MEDLINE via PubMed found no similar reports with respect to the efficacy of first-line chemotherapy, GC risk, or prognosis.

Notably, although we identified SLCO1B1 rs4149056 as a prognostic factor for OS in MGC patients treated with first-line EOF, we failed to detect any correlation between SLCO1B1 rs4149056 and PFS. There are two possible reasons for this apparent discrepancy. First, SLCO1B1 rs4149056 may only be a prognostic factor in GC patients, and may not affect the short-term efficacy of first-line chemotherapy. Second, CPT-11 or paclitaxel were administered as the main second- or third-line chemotherapy regimens in the present study; as noted above, SLCO1B1 rs4149056 has been associated with the metabolism 
Table II. Associations between patient characteristics and survival.

\begin{tabular}{|c|c|c|c|c|c|}
\hline Characteristics & Number of patients (\%) & Median OS & P-value & Median PFS & P-value \\
\hline \multicolumn{6}{|l|}{ Age (years) } \\
\hline$\leq 60$ & $80(74.1)$ & 465 & \multirow[t]{2}{*}{0.916} & 159 & \multirow[t]{2}{*}{0.176} \\
\hline$>60$ & $28(25.9)$ & 403 & & 187 & \\
\hline \multicolumn{6}{|l|}{ Sex } \\
\hline Male & $64(59.3)$ & 534 & \multirow[t]{2}{*}{0.359} & 166 & \multirow[t]{2}{*}{0.163} \\
\hline Female & $44(40.7)$ & 372 & & 182 & \\
\hline \multicolumn{6}{|c|}{ ECOG performance status } \\
\hline 0 & $14(13.0)$ & 704 & \multirow[t]{3}{*}{0.153} & 240 & \multirow[t]{3}{*}{0.768} \\
\hline 1 & $89(82.4)$ & 367 & & 167 & \\
\hline 2 & $5(4.6)$ & 299 & & 237 & \\
\hline \multicolumn{6}{|l|}{ Histological grade } \\
\hline Moderate and high & $13(12.0)$ & 403 & \multirow[t]{3}{*}{0.226} & 156 & \multirow[t]{3}{*}{0.004} \\
\hline Low/undifferentiated & $66(61.2)$ & 875 & & 380 & \\
\hline Unclassified & $29(26.8)$ & 367 & & 180 & \\
\hline \multicolumn{6}{|l|}{ Number of tumor sites } \\
\hline 1 & $5(4.6)$ & 984 & \multirow[t]{3}{*}{0.076} & 545 & \multirow[t]{3}{*}{0.038} \\
\hline 2 & $8(7.4)$ & 570 & & 411 & \\
\hline$\geq 3$ & $95(88.0)$ & 372 & & 167 & \\
\hline \multicolumn{6}{|l|}{ Metastasis sites } \\
\hline Liver & & & & & \\
\hline Yes & $36(33.3)$ & 281 & \multirow[t]{2}{*}{0.004} & 169 & \multirow[t]{2}{*}{0.232} \\
\hline No & $72(66.7)$ & 570 & & 178 & \\
\hline \multicolumn{6}{|l|}{ Lung } \\
\hline Yes & $7(6.5)$ & 252 & \multirow[t]{2}{*}{0.997} & 169 & \multirow[t]{2}{*}{0.885} \\
\hline No & $101(93.5)$ & 444 & & 187 & \\
\hline \multicolumn{6}{|c|}{ Retroperitoneal lymph node } \\
\hline Yes & 45 & 372 & \multirow[t]{2}{*}{0.710} & 156 & \multirow[t]{2}{*}{0.033} \\
\hline No & 63 & 534 & & 192 & \\
\hline \multicolumn{6}{|l|}{ Ascites } \\
\hline Yes & 32 & 312 & \multirow[t]{2}{*}{0.101} & 126 & \multirow[t]{2}{*}{0.015} \\
\hline No & 76 & 534 & & 192 & \\
\hline \multicolumn{6}{|l|}{ Pleural effusion } \\
\hline Yes & 9 & 211 & \multirow[t]{2}{*}{0.001} & 144 & 0.054 \\
\hline No & 99 & 475 & & 178 & \\
\hline
\end{tabular}

Log-rank test. PFS, progression free survival; OS, overall survival.

of CPT-11 and paclitaxel, and rs4149056 may thus affect OS by influencing the efficacy of the second- or third-line regimens.

In our study, $A B C G 2$ (BCRP2) C421A rs2231142 was borderline-significantly associated with $\mathrm{PFS}(\mathrm{P}=0.083)$, though multivariate analysis did not identify it as an independent predictor in GC patients treated with EOF regimen. However, several previous studies reported significant relationships between $A B C G 2$ (BCRP2) C421A rs2231142 and the toxicity or efficacy of oxaliplatin or anthracyclines. Custodio et al revealed that $A B C G 2$ rs3114018 was associated with oxaliplatin-induced peripheral neuropathy in patients with stage II-III colon cancer (32), while breast cancer patients with an $A B C G 2$ rs2231142 A allele reportedly showed better responses to anthracycline-based neoadjuvant chemotherapy (16). Ghafouri et al also showed that the ABCG2 rs22311442 A allele was associated with stronger responses to anthracyclines and paclitaxel (33). Overall, these three studies indicated that patients with an ABCG2 rs22311442 A allele showed better responses to anthracyclines and paclitaxel. Although the current univariate analysis failed to find an association between $A B C G \mathrm{rs} 22311442$ and PFS, there was a nonsignificant tendency towards longer PFS among rs22311442 AA/AC compared with rs22311442 $\mathrm{CC}$ patients. There are three possible reasons for this apparent discrepancy. First, it is possible that the sample-size was too small to demonstrate any significant difference between the survival trends of patients with rs22311442 A and C alleles, respectively. Second, the previous studies involved patients with colon cancer or breast cancer, rather than GC, and the results may thus have been affected by this tumor heterogeneity. Third, the EOF regimen contains epirubicin, oxaliplatin, and 5FU. 


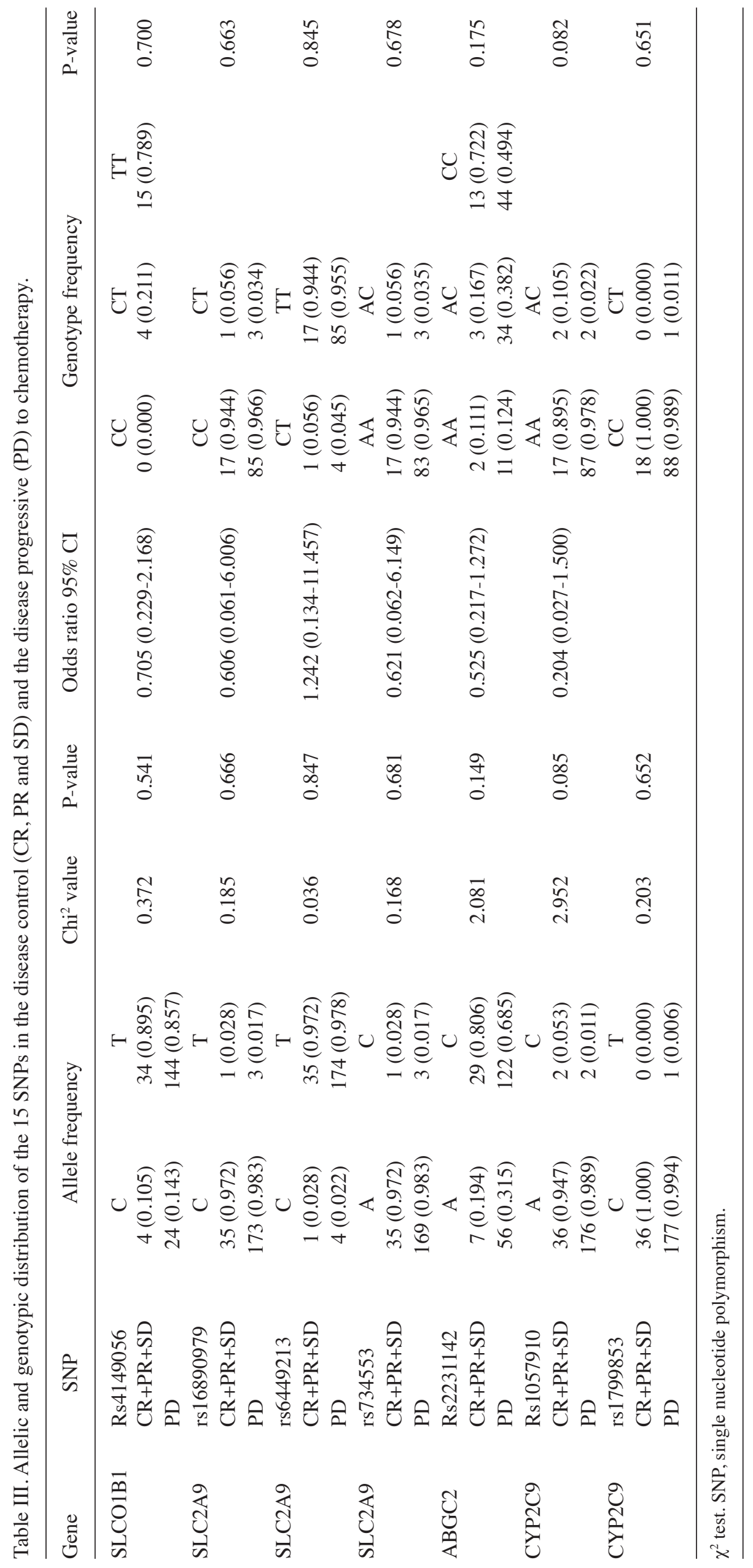


Table IV. Univariate survival analysis of SNPs and overall survival/progression free survival time.

\begin{tabular}{|c|c|c|c|c|c|c|}
\hline SNPs & Median OS & $95 \% \mathrm{CI}$ & P-value & Median PFS & $95 \% \mathrm{CI}$ & P-value \\
\hline \multicolumn{7}{|c|}{ SLCO1B1 rs4149056 } \\
\hline $\mathrm{TT}$ & 312.0 & $178.0-445.9$ & \multirow[t]{2}{*}{0.039} & 173.0 & $142.7-203.2$ & \multirow[t]{2}{*}{0.760} \\
\hline $\mathrm{CC}+\mathrm{CT}$ & 565.0 & 108.9-1021.0 & & 179.0 & $157.6-200.3$ & \\
\hline \multicolumn{7}{|c|}{ SLC2A9 rs16890979 } \\
\hline $\mathrm{CC}$ & 465.0 & $303.1-626.8$ & \multirow[t]{2}{*}{0.301} & 176.0 & $156.7-195.2$ & \multirow[t]{2}{*}{0.427} \\
\hline $\mathrm{TC}$ & 189.0 & $0.0-383.6$ & & 162.0 & $0.0-353.6$ & \\
\hline \multicolumn{7}{|c|}{ SLC2A9 rs6449213 } \\
\hline $\mathrm{CT}$ & 265.0 & $94.0-435.9$ & \multirow[t]{2}{*}{0.161} & 162.0 & $55.8-268.1$ & \multirow[t]{2}{*}{0.257} \\
\hline $\mathrm{TT}$ & 465.0 & $304.2-625.7$ & & 176.0 & $161.4-190.5$ & \\
\hline \multicolumn{7}{|c|}{ SLC2A9 rs734553 } \\
\hline AA & 444.0 & $307.7-580.2$ & \multirow[t]{2}{*}{0.282} & 173.0 & $154.2-191.7$ & \multirow[t]{2}{*}{0.489} \\
\hline $\mathrm{CA}$ & 189.0 & $0.0-383.6$ & & 162.0 & $0-353.6$ & \\
\hline \multicolumn{7}{|c|}{ ABGC2 rs2231142 } \\
\hline $\mathrm{CC}$ & 444.0 & $293.2-594.7$ & \multirow[t]{2}{*}{0.750} & 167.0 & $144.1-189.8$ & \multirow[t]{2}{*}{0.083} \\
\hline $\mathrm{AA}+\mathrm{CA}$ & 475.0 & $128.5-821.4$ & & 182.0 & $138.1-225.8$ & \\
\hline \multicolumn{7}{|c|}{ CYP2C9 rs1057910 } \\
\hline $\mathrm{AA}$ & 444.0 & $289.8-598.1$ & \multirow[t]{2}{*}{0.382} & 176 & $156.8-195.1$ & \multirow[t]{2}{*}{0.311} \\
\hline $\mathrm{CA}$ & 295.0 & $0.0-727.6$ & & 41 & $0.0-202.7$ & \\
\hline \multicolumn{7}{|c|}{ CYP2C9 rs1799853 } \\
\hline $\mathrm{CC}$ & 465.0 & $272.9-657.0$ & \multirow[t]{2}{*}{0.711} & 173.0 & $153.6-192.3$ & \multirow[t]{2}{*}{0.750} \\
\hline $\mathrm{CT}$ & 444.0 & - & & 178.0 & - & \\
\hline
\end{tabular}

Log-rank test. PFS, progression-free survival; OS, overall survival; HR, hazards ratio; CI, confidence interval; SNP, single nucleotide polymorphism.

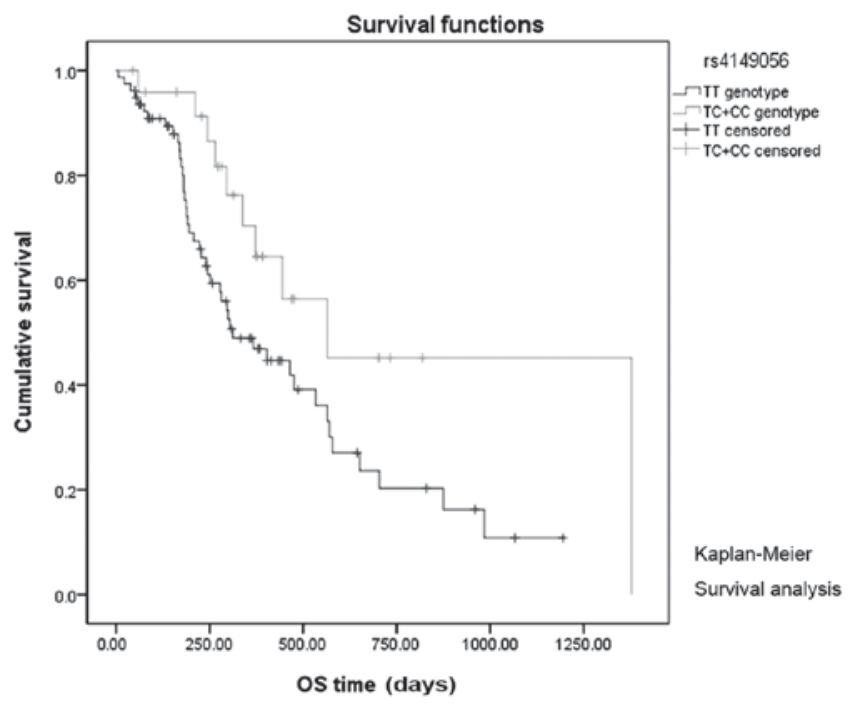

Figure 1. Kaplain-Meier OS curves in patients with different SLCO1B1 rs4149056 genotypes. OS, overall survival.

Custodio showed an association between $A B C G 2$ rs22311442 and oxaliplatin toxicity rather than oxaliplatin response, which differed from our current study.

Evidence suggests that some CYP450 enzyme family members affect 5FU metabolism (34-37). 5FU was reported to reduce the ability to metabolize a CYP2C9 probe drug (38).

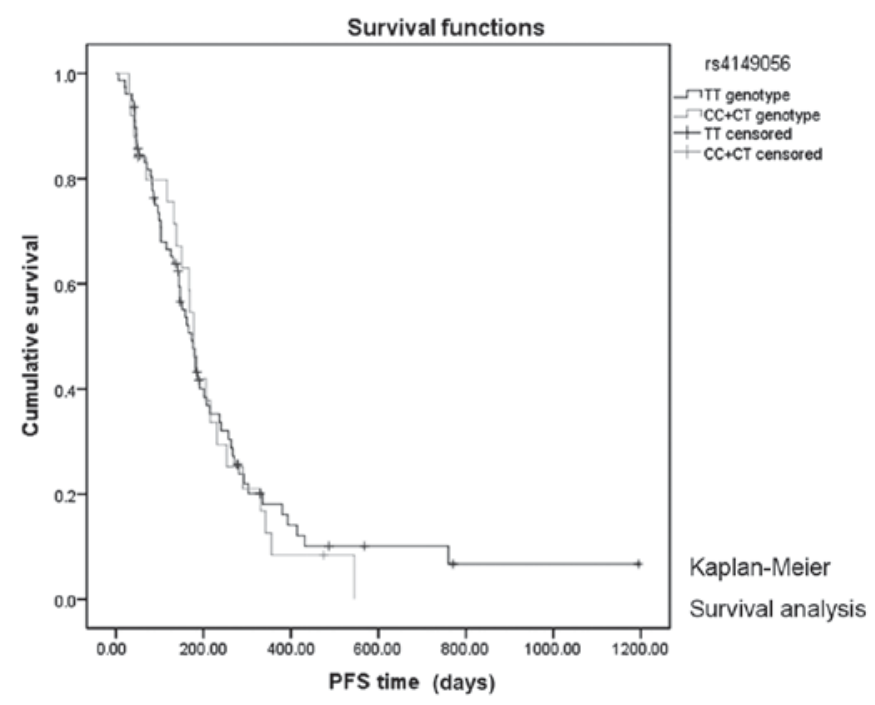

Figure 2. Kaplain-Meier PFS curves in patients with different SLCO1B1 rs4149056 genotypes. PFS, progression-free survival.

Moreover, several studies have indicated that 5FU can down-regulate the expression of CYP enzymes, including CYP2C9 and CYP2C19 (39,40). However, although CYP2C9 and CYP2C19 have been shown to influence 5FU metabolism in vitro, these results have not yet been verified in clinical studies. Furthermore, no studies have reported on the relationship 
Table V. Multi-factorial analysis of prognostic factors for PFS and OS.

\begin{tabular}{lcccc}
\hline & \multicolumn{2}{c}{ OS } & & PFS \\
\cline { 2 - 5 } Clinical factor & P-value & HR 95\% CI & P-value & HR 95\% CI \\
\hline rs4149056 TT & 0.014 & $2.565(1.215-5.415)$ & - & - \\
Grade & - & - & 0.221 & - \\
PLN & - & - & 0.003 & $2.041(1.271-3.278)$ \\
Ascites & 0.050 & $0.508(0.258-0.999)$ & 0.436 & $0.818(0.494-1.355)$ \\
Pleural effusion & 0.016 & $0.363(0.159-0.827)$ & 0.071 & $0.497(0.232-1.061)$ \\
Liver & 0.002 & $0.372(0.179-0.703)$ & - & - \\
Number of sites & - & - & 0.200 & - \\
rs2231142 CC & - & - & 0.342 & $1.239(0.796-1.929)$ \\
\hline
\end{tabular}

Cox proportional hazards model. PFS, progression-free survival; OS, overall survival; HR, hazards ratio; CI, confidence interval; PLN, retroperitoneal lymph node.

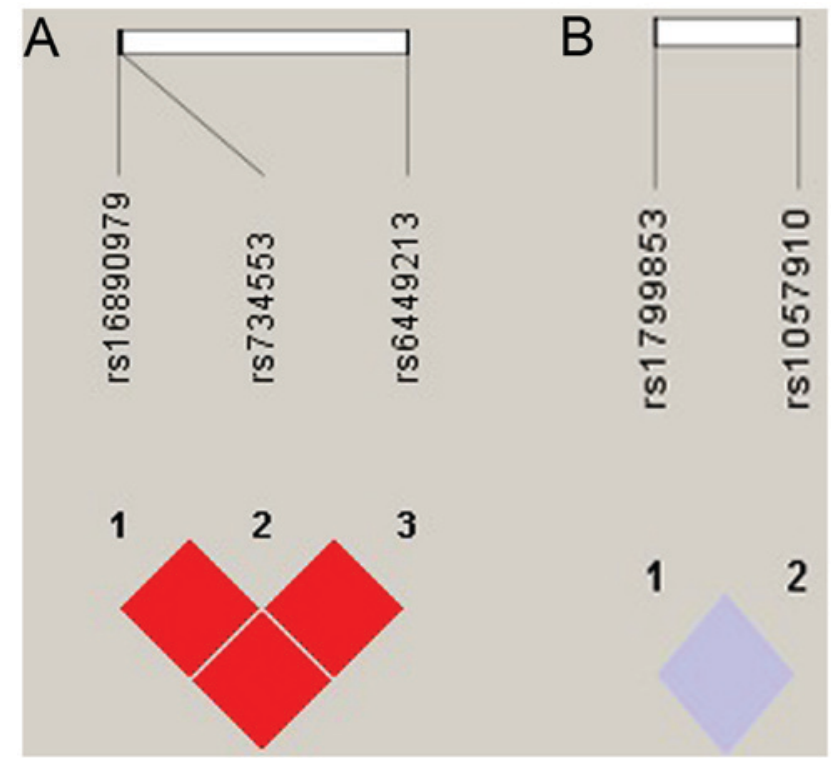

Figure 3. Haploview linkage disequilibrium. Linkage disequilibrium for haplotype blocks within (A) the SLC2A9 SNPs rs16890979, rs734553 and rs6449213, (B) the CYP2C9 SNPs rs1057910 and rs1799853.

between 5FU efficacy and SNPs in CYP2C9 or CYP2C19. Our results showed that all 108 blood samples had the same genotypic distributions of $C Y P 2 C 9$ and $C Y P 2 C 19$ SNPs, except for CYP2C9 rs1057910, which was not significantly associated with PFS or OS. The roles of CYP2C9 and CYP2C19 in 5FU metabolism thus currently remain unclear.

There were several limitations to the present study. First, we only analyzed some of the genes related to the CYP, SLC, and $\mathrm{ABC}$ families, and any associations between the remaining untested genes and GC remain unknown. Second, we only detected selected polymorphisms for each target agent, and other potentially related polymorphisms may have been missed. Third, the sample size was relatively small. The conclusions of this study therefore require verification in further studies.

In conclusion, the present study identified an association between the SLCO1B1 rs4149056 SNP and clinical outcomes of MGC patients treated with EOF chemotherapy. The resulting risk model successfully divided patients into low-risk and high-risk groups, with a significant difference in OS, but not PFS. SLCO1B1 rs4149056 is therefore a prognostic, but not a predictive factor in MGC patients treated with EOF. Further studies are required to validate our results and to detect other potential prognostic sites in SLCO1B1.

\section{Acknowledgements}

Not applicable.

\section{Funding}

This study was funded by The National Key Research and Development Program of China (grant no. 2017YFC1308900).

\section{Availability of data and materials}

All data generated or analysed during this study are included in this published article.

\section{Authors' contributions}

WF and XL performed the statistical analysis and wrote the article. XZhu and ZC designed and managed the research. XZha and $\mathrm{MH}$ performed the experiments. WG and JY assisted with the research design.

\section{Ethics approval and consent to participant}

Informed consent was been obtained from all participants. The study was approved by the Ethics Committee of Fudan University Shanghai Cancer.

\section{Patient consent for publication}

Not applicable. 


\section{Competing interests}

The authors declare that they have no competing interests.

\section{References}

1. Huang L, Zhang T, Xie C, Liao X, Yu Q, Feng J, Ma H, Dai J, Li M, Chen J, et al: SLCO1B1 and SLC19A1 gene variants and irinotecan-induced rapid response and survival: A prospective multicenter pharmacogenetics study of metastatic colorectal cancer. PLoS One 8: e77223, 2013.

2. De Mattia E, Toffoli G, Polesel J, D'Andrea M, Corona G, Zagonel V, Buonadonna A, Dreussi E and Cecchin E: Pharmacogenetics of $\mathrm{ABC}$ and SLC transporters in metastatic colorectal cancer patients receiving first-line FOLFIRI treatment. Pharmacogenet Genomics 23: 549-557, 2013.

3. Ramsey LB, Panetta JC, Smith C, Yang W, Fan Y, Winick NJ, Martin PL, Cheng C, Devidas M, Pui CH, et al: Genome-wide study of methotrexate clearance replicates SLCO1B1. Blood 121: 898-904, 2013

4. Radtke S, Zolk O, Renner B, Paulides M, Zimmermann M, Möricke A, Stanulla M, Schrappe M and Langer T: Germline genetic variations in methotrexate candidate genes are associated with pharmacokinetics, toxicity, and outcome in childhood acute lymphoblastic leukemia. Blood 121: 5145-5153, 2013.

5. Treviño LR, Shimasaki N, Yang W, Panetta JC, Cheng C, Pei D, Chan D, Sparreboom A, Giacomini KM, Pui CH, et al: Germline genetic variation in an organic anion transporter polypeptide associated with methotrexate pharmacokinetics and clinical effects. J Clin Oncol 27: 5972-5978, 2009.

6. Innocenti F, Kroetz DL, Schuetz E, Dolan ME, Ramírez J, Relling M, Chen P, Das S, Rosner GL and Ratain MJ Comprehensive pharmacogenetic analysis of irinotecan neutropenia and pharmacokinetics. J Clin Oncol 27: 2604-2614, 2009.

7. Teft WA, Welch S, Lenehan J, Parfitt J, Choi YH, Winquist E and Kim RB: OATP1B1 and tumour OATP1B3 modulate exposure toxicity, and survival after irinotecan-based chemotherapy. Br J Cancer 112: 857-865, 2015

8. Svoboda M, Wlcek K, Taferner B, Hering S, Stieger B, Tong D, Zeillinger R, Thalhammer T and Jäger W: Expression of organic anion-transporting polypeptides $1 \mathrm{~B} 1$ and $1 \mathrm{~B} 3$ in ovarian cancer cells: Relevance for paclitaxel transport. Biomed Pharmacother 65: 417-426, 2011.

9. Zhang HN, He XL, Wang C, Wang Y, Chen YJ, Li JX, Niu CH and Gao P: Impact of SLCO1B1 521T>C variant on leucovorin rescue and risk of relapse in childhood acute lymphoblastic leukemia treated with high-dose methotrexate. Pediatr Blood Cancer 61: 2203-2207, 2014

10. Ramsey LB, Bruun GH, Yang W, Treviño LR, Vattathil S Scheet P, Cheng C, Rosner GL, Giacomini KM, Fan Y, et al: Rare versus common variants in pharmacogenetics: SLCO1B1 variation and methotrexate disposition. Genome Res 22: 1-8, 2012.

11. Lima A, Bernardes M, Azevedo R, Monteiro J, Sousa H Medeiros R and Seabra V: SLC19A1, SLC46A1 and SLCO1B1 polymorphisms as predictors of methotrexate-related toxicity in Portuguese rheumatoid arthritis patients. Toxicol Sci 142: 196-209, 2014

12. Yuan SQ, Zhou ZW, Liang YJ, Fu LW, Chen G, Qiu HB and Zhang LY: Correlation of chemosensitivity tested using histoculture drug response assay to expression of multidrug resistance genes and proteins in colorectal cancer tissues. Ai Zheng 28 : 932-938, 2009.

13. Cortez MA, Scrideli CA, Yunes JA, Valera ET, Toledo SR, Pavoni-Ferreira PC, Lee ML, Petrilli AS, Brandalise SR and Tone LG: mRNA expression profile of multidrug resistance genes in childhood acute lymphoblastic leukemia. Low expression levels associated with a higher risk of toxic death. Pediatr Blood Cancer 53: 996-1004, 2009.

14. Zhou S, Liao L, Chen C, Zeng W, Liu S, Su J, Zhao S, Chen M, Kuang Y, Chen X and Li J: CD147 mediates chemoresistance in breast cancer via ABCG2 by affecting its cellular localization and dimerization. Cancer Lett 337: 285-292, 2013.

15. Wang Z, Wang N, Li W, Liu P, Chen Q, Situ H, Zhong S, Guo L, Lin Y, Shen J and Chen J: Caveolin-1 mediates chemoresistance in breast cancer stem cells via $\beta$-catenin/ABCG2 signaling pathway. Carcinogenesis 35: 2346-2356, 2014.
16. Wu H, Liu Y, Kang H, Xiao Q, Yao W, Zhao H, Wang E and Wei M: Genetic variations in ABCG2 gene predict breast carcinoma susceptibility and clinical outcomes after treatment with anthracycline-based chemotherapy. Biomed Res Int 2015: 279109,2015

17. Won HJ, Ha TK, Kwon SJ, Cho HY, Hur SJ, Baik HH, Suh SI, Ha E and Kim YH: Differential effects of 5-fluorouracil on glucose transport and expressions of glucose transporter proteins in gastric cancer cells. Anticancer Drugs 21: 270-276, 2010.

18. Berlth F, Mönig S, Pinther B, Grimminger P, Maus M, Schlösser H, Plum P, Warnecke-Eberz U, Harismendy O, Drebber U, et al: Both GLUT-1 and GLUT-14 are independent prognostic factors in gastric adenocarcinoma. Ann Surg Oncol 22 (Suppl 3): S822-S831, 2015

19. Schlößer HA, Drebber U, Urbanski A, Haase S, Baltin C, Berlth F, Neiß S, von Bergwelt-Baildon M, Fetzner UK, Warnecke-Eberz U, et al: Glucose transporters 1, 3, 6, and 10 are expressed in gastric cancer and glucose transporter 3 is associated with UICC stage and survival. Gastric Cancer 20: 83-91, 2017.

20. Dees EC and Watkins PB: Role of cytochrome P450 phenotyping in cancer treatment. J Clin Oncol 23: 1053-1055, 2005.

21. Jernström H, Bågeman $\mathrm{E}$, Rose $\mathrm{C}$, Jönsson PE and Ingvar C: CYP2C8 and CYP2C9 polymorphisms in relation to tumour characteristics and early breast cancer related events among 652 breast cancer patients. Br J Cancer 101: 1817-1823, 2009.

22. Boruban MC, Yasar U, Babaoglu MO, Sencan O and Bozkurt A: Tamoxifen inhibits cytochrome P450 2C9 activity in breast cancer patients. J Chemother 18: 421-424, 2006.

23. Seredina TA, Goreva OB, Talaban VO, Grishanova AY and Lyakhovich VV: Association of cytochrome P450 genetic polymorphisms with neoadjuvant chemotherapy efficacy in breast cancer patients. BMC Med Genet 13: 45, 2012.

24. Jamieson D, Lee J, Cresti N, Jackson R, Griffin M, Sludden J, Verrill M and Boddy AV: Pharmacogenetics of adjuvant breast cancer treatment with cyclophosphamide, epirubicin and 5-fluorouracil. Cancer Chemother Pharmacol 74: 667-674, 2014

25. Melanson SE, Stevenson K, Kim H, Antin JH, Court MH, Ho VT, Ritz J, Soiffer RJ, Kuo FC, Longtine JA and Jarolim P: Allelic variations in CYP2B6 and CYP2C19 and survival of patients receiving cyclophosphamide prior to myeloablative hematopoietic stem cell transplantation. Am J Hematol 85: 967-971, 2010.

26. Beelen K, Opdam M, Severson TM, Koornstra RH, Vincent AD, Hauptmann M, van Schaik RH, Berns EM, Vermorken JB, van Diest PJ and Linn SC: CYP2C19 2 predicts substantial tamoxifen benefit in postmenopausal breast cancer patients randomized between adjuvant tamoxifen and no systemic treatment. Breast Cancer Res Treat 139: 649-655, 2013.

27. van Schaik RH, Kok M, Sweep FC, van Vliet M, van Fessem M, Meijer-van Gelder ME, Seynaeve C, Lindemans J, Wesseling J, Van't Veer LJ, et al: The CYP2C19*2 genotype predicts tamoxifen treatment outcome in advanced breast cancer patients. Pharmacogenomics 12: 1137-1146, 2011.

28. Komatsu T, Yamazaki H, Shimada N, Nakajima M and Yokoi T: Roles of cytochromes P450 1A2, 2A6, and 2C8 in 5-fluorouracil formation from tegafur, an anticancer prodrug, in human liver microsomes. Drug Metab Dispos 28: 1457-1463, 2000.

29. Faul F, Erdfelder E, Lang AG and Buchner A: G*Power 3: A flexible statistical power analysis program for the social, behavioral, and biomedical sciences. Behav Res Methods 39: 175-191, 2007.

30. Benjamini Y, Drai D, Elmer G, Kafkafi N and Golani I: Controlling the false discovery rate in behavior genetics research. Behav Brain Res 125: 279-284, 2001.

31. Niemi M, Pasanen MK and Neuvonen PJ: Organic anion transporting polypeptide 1B1: A genetically polymorphic transporter of major importance for hepatic drug uptake. Pharmacol Rev 63: 157-181, 2011.

32. Custodio A,Moreno-Rubio J, Aparicio J, Gallego-Plazas J, Yaya R, Maurel J, Higuera O, Burgos E, Ramos D, Calatrava A, et al: Pharmacogenetic predictors of severe peripheral neuropathy in colon cancer patients treated with oxaliplatin-based adjuvant chemotherapy: A GEMCAD group study. Ann Oncol 25: 398-403, 2014

33. Ghafouri H, Ghaderi B, Amini S, Nikkhoo B, Abdi M and Hoseini A: Association of ABCB1 and ABCG2 single nucleotide polymorphisms with clinical findings and response to chemotherapy treatments in Kurdish patients with breast cancer. Tumour Biol 37: 7901-7906, 2016.

34. Park SR, Kong SY, Nam BH, Choi IJ, Kim CG, Lee JY, Cho SJ, Kim YW, Ryu KW, Lee JH, et al: CYP2A6 and ERCC1 polymorphisms correlate with efficacy of S-1 plus cisplatin in metastatic gastric cancer patients. Br J Cancer 104: 1126-1134, 2011. 
35. Park SR,Hong YS,Lim HS, Seong MW, Kong SY,Kim SY,Park Y and Jung KH: Phase I clinical and pharmacokinetic/pharmacogenetic study of a triplet regimen of S-1/irinotecan/oxaliplatin in patients with metastatic colorectal or gastric cancer. Cancer Chemother Pharmacol 72: 953-964, 2013.

36. Kim YW, Kim MJ, Ryu KW, Lim HS, Lee JH, Kong SY, Lee JS, Choi IJ, Kim CG, Lee JY, et al: A phase II study of perioperative S-1 combined with weekly docetaxel in patients with locally advanced gastric carcinoma: Clinical outcomes and clinicopathological and pharmacogenetic predictors for survival. Gastric Cancer 19: 586-596, 2016.

37. Kong SY, Lim HS, Nam BH, Kook MC, Kim YW, Ryu KW, Lee JH, Choi IJ, Lee JS, Park YI, et al: Association of CYP2A6 polymorphisms with S-1 plus docetaxel therapy outcomes in metastatic gastric cancer. Pharmacogenomics 10: 1147-1155, 2009.

38. Karadag O, Babaoglu MO, Altundag K, Elkiran T, Yasar U and Bozkurt A: 5-Fluorouracil-induced coronary spasm: May inhibition of hyperpolarization factors produced by CYP2C enzymes be the cause? Oncology 66: 510-511, 2004.
39. Helsby NA, Lo WY, Thompson P and Laking GR: Do 5-fluorouracil therapies alter CYP2C19 metaboliser status? Cancer Chemother Pharmacol 66: 405-407, 2010.

40. Afsar A, Lee C and Riddick DS: Modulation of the expression on constitutive rat hepatic cytochrome $\mathrm{P} 450$ isozymes by 5 -fluorouracil. Can J Physiol Pharmacol 74: 150-156, 1996.

This work is licensed under a Creative Commons Attribution-NonCommercial-NoDerivatives 4.0 International (CC BY-NC-ND 4.0) License. 